\title{
Preschoolers' Understanding of the Role of Communication and Cooperation in Establishing Property Rights
}

\author{
Federico Rossano, Lydia Fiedler, and Michael Tomasello \\ Max Planck Institute for Evolutionary Anthropology, Leipzig, Germany
}

\begin{abstract}
Property as a social "agreement" comprises both a communicative component, in which someone makes a claim that she is entitled to some piece of property, and a cooperative component, in which others in the community respect that claim as legitimate. In the current study, preschool children were (a) given the opportunity to mark some objects as "theirs" (to claim them in the face of other fictitious children who would supposedly enter the room later); and (b) confronted with stickers in various spatial arrangements (e.g., piled up neatly vs. scattered), told that a fictitious child had previously chosen some for herself but had to suddenly leave the room, and then invited first to choose some stickers for themselves and second to identify which stickers had already been claimed by the fictitious child. Five-year-olds but not 3 -year-olds were skillful in both of these tasks, demonstrating an understanding of the crucial role of communication in asserting property claims and the crucial role of cooperation in respecting them.
\end{abstract}

Keywords: communication, cooperation, ownership, property, social cognition

Supplemental materials: http://dx.doi.org/10.1037/a0038493.supp

There is a common misconception of property as a dyadic relation between a person and a thing. While this may accurately characterize physical possession, property as a social "agreement" represents a triadic relation between two or more people with respect to a thing (Singer, 2010). This agreement comprises two key components: (a) a communicative component in which someone makes a claim that she is entitled to some piece of property (Rose, 1985), and (b) a cooperative component in which others in the community respect that claim as legitimate (Rose, 2007). Concepts such as entitle and legitimate highlight the socially normative character of property claims as cooperative acts.

For example, consider the simple situation argued about in various legal and philosophical discussions (see, e.g., Nozick, 1974; Sugden, 1986, 1989). Driftwood washes unowned upon a beach. If I gather up various pieces and intentionally place them in a pile, the fact of this intentional placing communicates to other beachcombers that I had first possession of the driftwood, I did some work to pile the pieces up, and therefore I am claiming property of it. Placing my sweater on top of the pile would indicate this even more strongly. The key is altering the natural arrangement of objects intentionally with the specific communicative

This article was published Online First December 15, 2014.

Federico Rossano, Lydia Fiedler, and Michael Tomasello, Department of Developmental and Comparative Psychology, Max Planck Institute for Evolutionary Anthropology, Leipzig, Germany.

We thank all the children and day care centers involved in this work for their cooperation, and we thank Claudia Salomo, Juliane Richter, and Christiane Markmann for their help in recruiting children and data collection.

Correspondence concerning this article should be addressed to Federico Rossano, Department of Developmental and Comparative Psychology, Max Planck Institute for Evolutionary Anthropology, Deutscher Platz 6, 04103 Leipzig, Germany. E-mail: federico_rossano@eva.mpg.de intent of claiming property, believing that others will comprehend and respect it. In general, communicative signals of property may be less conventional (e.g., placing objects apart from others in a special location) or more conventional (e.g., placing one's own clothing on top of them or writing one's initials on them).

In small group settings, the communicative component may be backgrounded as everyone knows that a particular object belongs to a particular person and that this person wishes to maintain that property relationship. But still, even in such settings, if there is a question about ownership, the owner must make her claim explicitly. In the public domain and larger group settings, explicit claims are often unnecessary because ownership is indicated conventionally. For example, expensive commercial items in good working order are simply assumed to be owned by someone (e.g., a car), unless there are special circumstances indicating that they have been abandoned (e.g., a broken down car left in a junkyard). But in the absence of such implicit cultural signals, an individual who wishes to maintain ownership of something while at the same time relinquishing physical control, must assert her claim in some way explicitly. This is true for permanent ownership-for example, I write my child's name on the towels she takes to summer campand for temporary claims as well-for example, I leave my coat in a seat at the cinema to claim temporary ownership while I am at the toilet. Interestingly and importantly, to relinquish ownership when others might assume it, I must also perform some explicit act that communicates my new attitude (e.g., throwing it in a trash can; see Rossano \& Tomasello, 2014).

There is a long history of animal and human research on "territoriality" in which individuals "mark" spaces or objects they are prepared to defend (e.g., Altman, 1970; Ardrey, 1966; Becker, 1973; Carpenter, 1958; Edney, 1974; Lorenz, 1966; Sommer \& Becker, 1968). Goffman (1971), in particular, has made explicit the connection between territorial behavior and property by emphasizing the fact that people tend to "claim" territories, that is, 
they experience an entitlement to possess, control, use, and dispose of them. Several studies have shown that leaving personal items on a space at a public table or a public chair or a seat at a cafeteria are highly effective in defending those territories and keeping people away (Becker, 1973; Edney \& Jordan-Edney, 1974; Shaffer \& Sadowski, 1975; Sommer \& Becker, 1968).

In recent years, much has been learned about how young children develop notions of possession and ownership. In one line of research, for example, it has been found that preschool-aged children are capable of inferring who is the owner of an object by relying on first possession (e.g., who holds an object at the beginning of a story, see Friedman \& Neary, 2008); on control of permission (e.g., who says whether others can use an object, see Neary, Friedman, \& Burnstein, 2009); and more generally on the object's history, not just when personally witnessed but also when obtained via others' verbal testimony (Blake, Ganea, \& Harris, 2012; Friedman, Van de Vondervoort, Defeyter, \& Neary, 2013; Gelman, Manczak, \& Noles, 2012). And already by 3 years of age, young children believe that human-made objects (e.g., a ball, a toy car) are more likely to be owned than natural kinds (e.g., leaves, pine cones; Neary, Van de Vondervoort, \& Friedman, 2012).

In a second line of research, preschool children show an understanding of who has the right to own things (Hook, 1993; Keil, Gelman, Noles, \& Bloom, 2012); what kind of object manipulations entail a transfer of ownership (Blake \& Harris, 2009; Kanngiesser, Gjersoe, \& Hood, 2010; Rossano \& Tomasello, 2014); and the normative implications of owning or possessing something (Kanngiesser \& Hood, 2014; Kim \& Kalish, 2009; Rossano, Rakoczy, \& Tomasello, 2011).

Finally, in a third line of research, preschool children show an understanding of how property disputes are resolved (EisenbergBerg, Haake, \& Bartlett, 1981; Eisenberg-Berg, Haake, Hand, \& Sadalla, 1979; Hay, 2006; Ross, 1996, 2013; Smetana, 1984). Overall, there is general agreement that children's understanding of the basics of property, especially in relation to the normative obligations it creates, comes to relative maturity between the ages of 3 and 5 .

However, with regard to the specific question of young children's comprehension and production of communicative signals making property claims (other than verbal assertions such as "mine" and other possession terms) very little is known. Of special importance, there are no existing studies of children's understanding of communicative signals of property used to claim ownership while physical possession has been relinquished. In the current study, therefore, we looked at 3- and 5-year-olds' abilities to produce and comprehend such signals. For production, the child was told that she could claim some objects, but that she must leave them in the room for later retrieval-and other children would be coming soon to do the same thing for themselves. We observed the child's communicative behavior in this scenario. For comprehension, the child was told that another child had already claimed some objects for herself but had left the room momentarily without taking the objects away, and then the child encountered the objects spatially arranged in various ways in accordance with different potential communicative strategies. In this case, we observed to what degree the child would recognize spatial arrangements as property claims and to what degree she would cooperate and respect those claims by choosing alternative objects.

\section{Method}

\section{Participants}

Participants were 40 3-year-olds (mean age $=42$ months, range $=40-44$ months, 20 girls) and 405 -year-olds (mean age $=$ 66 months, range $=64-68$ months, 20 girls). An additional two children (a 3-year-old and a 5-year-old, both boys) were tested but excluded from the final sample because they were uncooperative during the testing phase. Children were recruited from urban day care centers, came from mixed socioeconomic backgrounds, and were native German speakers.

\section{Design}

In a within-subject design, all children were tested in one study with two phases: production and comprehension. All children received both phases. The production phase included two trials, one before and one after the comprehension phase. The comprehension phase included a between-subjects condition: in the informed condition the child was told that other children had already claimed some objects, whereas in the ignorant (control) condition, they were not told this (to control for children's natural preferences for certain spatial arrangements of objects). Children were also verbally asked during this phase to identify those arrangements of objects that indicated a claim of ownership. All children were thus tested in the following ABA order: Production 1st trial $\rightarrow$ Comprehension (Respecting property + Identifying property) $\rightarrow$ Production 2nd trial.

\section{Production Phase}

The production phase tested how children communicate to absent strangers a property claim over an object. Each child was tested with two items (order counterbalanced), with one trial per item. The items were the target objects that the child would claim property of (to keep control of them for later use): a chair (chair item) and some stuffed animals (animals item). The goal was to establish whether the different affordances of the objects (in particular in terms of ease of mobility) might lead to different means or motivations for marking them as their property.

After the child had gained possession of the target object(s), the experimenter communicated that they both should leave the room to get something that the experimenter had forgotten. However, the child was also told that another child (animals items) or other children (chair item) would likely enter the room during their absence. If the child did not react to this information, the experimenter provided up to three subsequent prompts of increasing level of specificity (see procedure for details), at intervals of $30 \mathrm{~s}$, to invite the child to take action.

\section{Comprehension Phase}

The comprehension study focused on children's comprehension of others' communications about property. Each child was tested with five different strategies based on how stickers were laid out 
on five chairs. They saw five chairs with 10 stickers distributed in different configurations on top of each chair. Seven stickers formed a circle, and the remaining 3 were positioned so as to suggest that someone else had already claimed them. The strategies represented strategies deployed by children tested in the piloting of the production study. The stickers selected to indicate a property claim were the most attractive ones in each set. The five strategies were (see also Figure 1):

(a) Apart: Three out of 10 stickers grouped and placed aside from the others;

(b) Mark: Three stickers had a transparent plastic cassette cover placed on top of them;

(c) Turned: Three stickers turned upside down;

(d) Stacked: Three stickers piled up on top of each other;

(e) Center: Three stickers put in the center of the sticker's circle.

For each strategy, we used 10 different stickers belonging to the same theme (e.g., fish, butterflies, smileys), and each strategy was always assigned the same theme. The order through which the child experienced the five strategies was counterbalanced across children using a Latin squares design.

The comprehension study had two parts: respecting property and identifying property. In the respecting property part, children were told that they could choose 3 stickers from each chair, but half of them were told that another child (Lena) had already chosen stickers from each chair but had left the room momentarily without taking the stickers away (informed condition). Lena was not mentioned to the other half of the children (ignorant condition). The hypothesis was that the children informed about Lena would be less likely than the others to choose the 3 "specially placed" stickers.

The identifying property part always followed the respecting property part and was designed to control whether the child's behavior in the previous part was driven by an understanding of which stickers Lena had claimed for herself. Here the children who had not been told about the prior presence of Lena in the room were now informed about it. All children were then asked to point to the stickers they thought were the ones that Lena had chosen.

\section{Procedure}

Children were tested in a child development laboratory. During a warm-up phase in which two experimenters (E1 and E2) played with the child, E1 and E2 repeatedly mentioned that other children were now playing in other rooms nearby. Before going to the test room, E1 invited the child to bring a scarf or a sweater along, mentioning that the testing room was cold and showing the child that she was wearing a scarf as well. This was designed to provide the child with the possibility to mark her property by placing something of her own on the claimed object. In what follows, the procedure starting with the chair trial is outlined.

\section{Production Phase, 1st Trial (Chair)}

In the test room, E1 and the child found a table with a small video player on top and three little chairs (see Figure 2). E1 then proposed watching a short animated movie together and asked the child to sit on the chair on the left. E1 then started the video. Thirty seconds into the movie, E1 interrupted the movie and asked the child whether she wanted to move to another chair. Sitting on the chair in the middle (in front of the video screen) provided a better view than sitting on any of the other two chairs. The child was therefore expected to want to move to the middle seat. If the child did not do so, it was considered that she had a preference for a lateral seat. This was aimed at increasing the child's desire to keep that seat during the test phase.

E1 then announced that they needed to go outside the room to get the second part of the movie. Before leaving the room, E1 mentioned that other children were about to come to the room to watch the film with them. E1 then asked the child where she wanted to sit when she would come back from picking up the second part of the video. After the child's answer, E1 then produced the following prompts:

(1) "Can you think of a way to keep the chair you have chosen?"

(2) "Can you think of a way the other children can see which chair you have chosen?"

(3) "Can you think of a way to prevent the other children from sitting on the chair you have already chosen?"

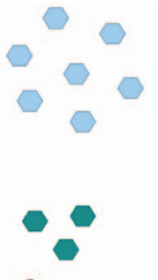

a

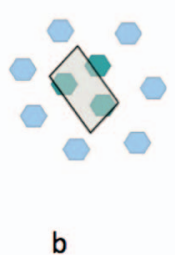

b
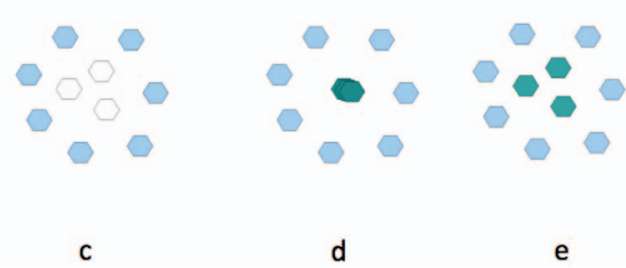

Figure 1. Abstract representation of the position of the stickers across strategies apart (a), mark (b), turned (c), stacked (d), and center (e). The 3 darker stickers identify the target stickers in each strategy (apart from turned, where the 3 target stickers are white because they have been turned upside down, and also to distinguish them from those in center). See the online article for the color version of this figure. 


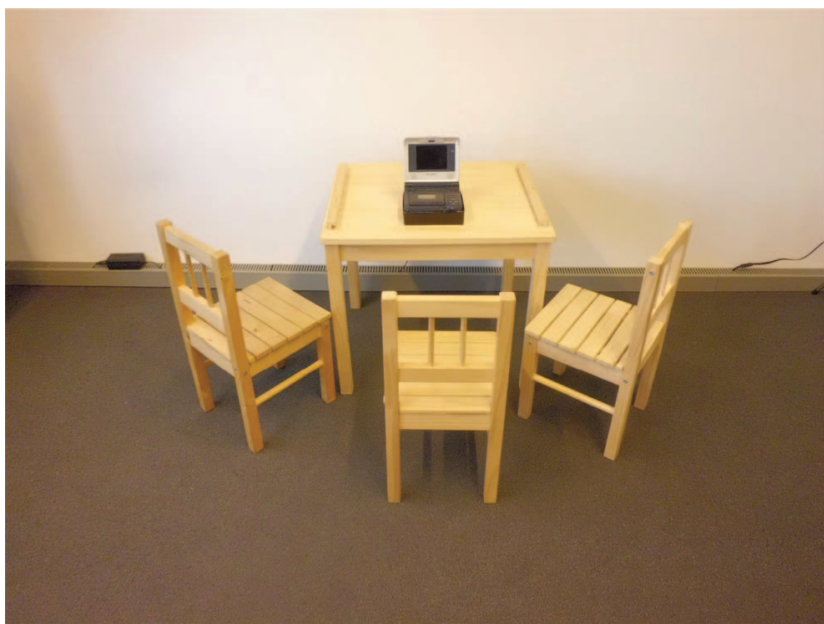

Figure 2. Set up of the chair item. See the online article for the color version of this figure.

The child was expected to implement some communicative behavior to mark the chair as her own. If she marked the chair as her property (claimed possession) after E1 had provided the first prompt, E1 directly led the child out to the hallway to get the videotape. If the child did not implement any "marking of property" in response to the prompt, after $30 \mathrm{~s}$ she was exposed to the second, and if necessary, to the third prompt (30 s later). Upon returning to the room, E2 told E1 and the child that the other children were too busy playing elsewhere and could not manage to come to the room and watch the film. E1 thus suggested watching the rest of the video before leaving the test room a second time to play a marble game.

\section{Comprehension Phase}

After the first production trial, the first part of the comprehension study (respecting property) followed. Upon returning into the same room used for the production phase, E2 asked the child to assist her with taking photographs of the stickers on five chairs located on one side of the room, opposite to the table and chairs used for the production phase. During the production phase, paper sheets had been placed on the chairs to prevent the children from seeing that there were stickers in the room and therefore to prevent distracting them. The photo-taking step was necessary for the following identifying property part and allowed the child to see the stickers on all chairs before being allowed to choose some for herself. After taking a photo of every chair with stickers, E1 asked E2 why all those stickers were there. For half of the children, E2 explained that another child, Lena, had previously been in the room and had chosen some stickers for herself (informed condition). However, she had to leave her stickers there while she went to get a container for them. E2 then left to look for Lena. For the other half of the children, no question was asked concerning the presence of stickers on the chairs, and no information about Lena was provided (ignorant condition).

In front of the first chair, E1 instructed half of the children as follows: "Lena has already chosen 3 stickers for herself. Now you may also choose 3 stickers for yourself." For the other half, E1 said, "You may choose 3 stickers for yourself." E1 then encouraged the child to choose 3 stickers from each chair. The child then proceeded to take 3 stickers from each chair and directly put the stickers into an envelope that E1 had provided.

Once the child was done picking 3 stickers from each chair for herself, the identifying property part began. E2 reentered the room, bringing back some large printed photos meant to represent the photos of the chairs that they had taken together at the beginning of the respecting property part (the photos used were actually the same ones for all participating children and had been taken before the beginning of the test). E2 put the pictures on each chair (on top of the stickers), asking the child to help her place the photos onto the chairs to which they belonged. While doing so, E2 pointed to one of the stickers on the chair and, while placing the photo on top, pointed to the same sticker on the photo, repeating in front of every chair that what the child was seeing on the photo was how it looked before the child had chosen the stickers for herself, when they took the photos together. After placing the photos on the chairs, the children in the ignorant condition were informed about Lena's prior presence in the room and the fact that she had chosen for herself 3 stickers from each chair. E1 then asked the child in front of each chair whether she could help E2 remember which stickers Lena had probably chosen. After asking about Lena's stickers in front of each chair, E1 suggested playing with the marble game outside. During their absence, E2 arranged the room for the second production trial.

\section{Production Phase, 2nd Trial (Animals)}

E1 led the child back to the test room. In front of the study room, E1 and the child found three cardboard boxes each containing 3 stuffed animals, visible to the child. E1 pointed out that other children had previously chosen 3 stuffed animals for themselves and put them in a box. E1 and the child then entered the study room where they saw 10 other stuffed animals spread randomly on the floor (see Figure 3).

After playing together with the stuffed animals, E1 told the child to choose 3 animals for herself. After the child's choice, E1 told the child that they needed to go to the hallway to get a box to put her stuffed animals in. The child would need both of her hands to carry her box, so she was asked to leave her stuffed animals in the test room. However, E1 also said that during their absence Lena

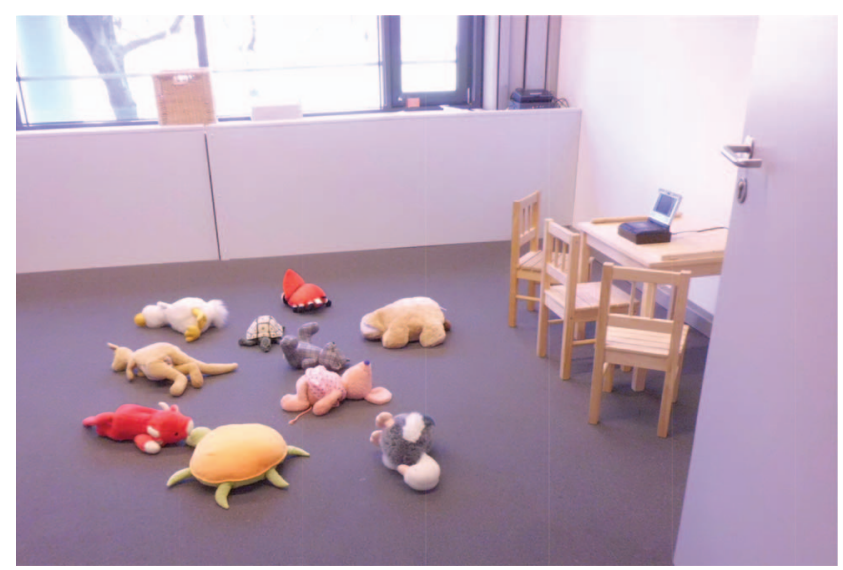

Figure 3. Set up for animals item. See the online article for the color version of this figure. 
might come in to play with the stuffed animals and choose 3 of them for herself. Then the same three prompts produced for the chair trial followed, substituting the word "chair" with "stuffed animals" and "other children" with "Lena." The prompts unfolded as in the chair trial.

After the child's answer, E1 and the child left the room to get a box. Returning to the test room with a box, they met E2 in the hallway, and she showed the child a box with 3 stuffed animals inside, explaining that Lena had just chosen 3 stuffed animals for herself (that were not the ones that the child had chosen). The child then put her stuffed animals in her box and left the test room with them. At the end of the test, the child was given a small toy in exchange for the box with the stuffed animals. In addition to the toy, the child could also take home the envelope with the stickers that she had chosen during the comprehension phase.

\section{Coding}

\section{Production Phase}

In the production phase, the measures were (a) whether the child found a way to communicate a property claim or not, and (b) which type of marking of objects she implemented. The solutions the children provided were divided in five categories, analogous to the categories used in the comprehension study:

(1) Apart: Child moves some stuffed animals apart from the other stuffed animals (or the chair apart from the table in the chair trial), yet not hiding them from sight but rather leaving them on chairs or the table, or in proximity of the remaining stuffed animals (often clustered in a group or aligned in a row);

(2) Mark: Child lays something of her own (e.g., her scarf/ jacket) on the stuffed animals/chair;

(3) Turned: Child turns the stuffed animals/chair around (or lays chair on its side);

(4) Stacked: Child piles the stuffed animals or chairs up;

(5) Central: Child moves chair close to the table or places the chosen stuffed animals in the center surrounded by the other stuffed animals.

The child could implement more than one solution to mark her property and therefore two (or more) options could be combined (e.g., "mark + apart" if the child puts the stuffed animals on a chair with her scarf on top of them). If one or more of the described above solutions occurred, the child scored 1 for marking property. The child scored 0 if she did not implement any of the above behaviors. An answer inviting E1 to sort the property problem for the child upon their return to the room was coded as 0 , as it relied on authority and left no mark on any of the objects for a stranger to observe and rely on during their absence. Furthermore, for each production trial, we coded when the children found a solution in relation to the three scaffolding instructions (after question 1, 2, or 3).

The child scored 0 if she attempted to hide the objects from the sight of incoming children. We did not consider this behavior to be a way of communicating property claims but rather comparable with ways of attempting to prevent access to resources. When children hid objects, they did so by placing them under the table and behind the chairs, in corners far away from the rest of the similar objects or on the windowsill behind other objects (often announcing to E1 that they were going to hide them).

\section{Comprehension Phase}

The comprehension phase measured children's understanding of different ways in which an absent stranger could have claimed property. There were 3 target stickers per strategy (i.e., per chair) that had been marked in a certain way. We coded (a) how many target stickers each child chose for herself (respecting property) and (b) how many target stickers the child identified as already claimed by Lena (identifying property). In the respecting property part, we coded which stickers the children took, and in the identifying property part, we coded which stickers they pointed to.

\section{Reliability}

All sessions were videotaped with two cameras (one focusing on the chairs for the comprehension phase, the other one recording the rest of the room for the production study). Furthermore, photos of the chairs were taken following the respecting property tests, and video clips of each child identifying the owned stickers were recorded during every session of the comprehension study. There were two observers: One coded all 80 children. The second observer, blind to the point of the study, coded a random sample of $25 \%$ of the children $(n=20)$, that is, 10 children from each age group (5 who had been told about Lena in the respecting property part and 5 that had not been told about Lena). There was very high agreement $(k=0.85)$ between the two observers in the production study (concerning whether children had successfully marked the object as theirs). In the comprehension phase, there was perfect agreement $(k=1)$ in all five conditions for the respecting property part. There was almost perfect agreement $(k=0.95)$ in the identifying property part.

\section{Results}

\section{Production Phase}

Based on the odds ratio, 5-year-olds were 42.5 times, 95\% CI [10.6, 170.7], more likely than 3 -year-olds to communicate property rights to an absent peer by marking the objects in at least one trial (78\% of 5-year-olds, $M=.78, S D=.42$, vs. $8 \%$ of 3 -yearolds, $M=.08, S D=.27 ;$ Fisher's exact test $p<.001$ ). Exactly $30 \%$ of 5-year-olds marked their property in both production trials whereas no 3-year-olds did so. Note that 18 5-year-olds (in a total of 21 trials) and 103 -year-olds (in a total of 12 trials) attempted to hide the objects from the sight of incoming children. The attempts to hide the objects occurred more often when the item was an animal than when the item was a chair (16 vs. 5 trials for 5-yearolds and 8 vs. 4 trials for 3 -year-olds).

Overall, a generalized linear mixed model (GLMM) comprising age, item, and trial as fixed effects, gender as a control predictor, and subject as a random factor revealed a significant effect of age, $z=3.959, p<.001$, of trial, $z=2.038, p=.042$, and of item, $z=-2.299, p=.022$ (see Figure 4 and Supplementary Materials for further details on the GLMM). Gender did not have an effect, 


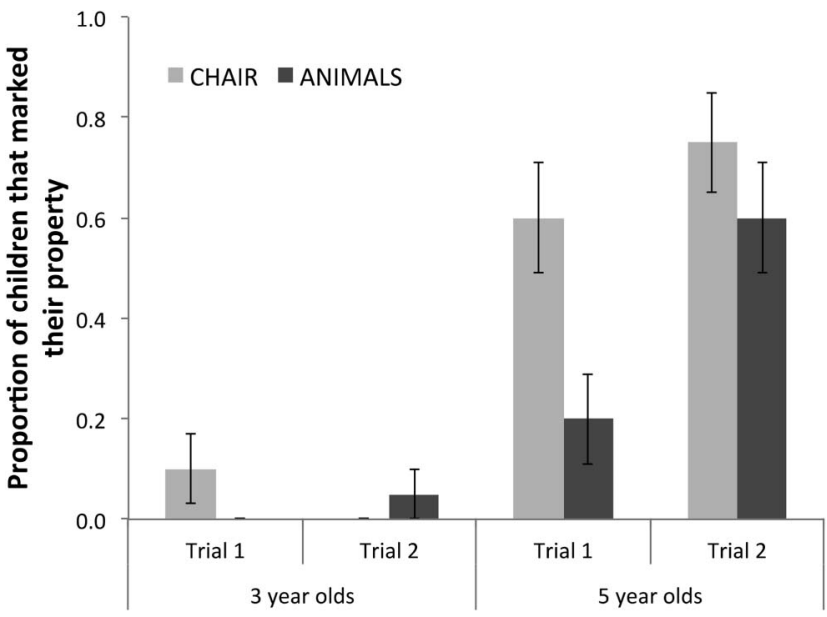

Figure 4. Proportion of children that marked their property in the production phase by age, trial, and item. Error bars represent standard error of the mean.

$z=1.237, p=.216$. Communication of property was more likely to occur with the item chair than with the items animals, and it was more likely to occur in the second trials, after having experienced the comprehension part. The 5-year-olds were much more likely than the 3-year-olds to implement some communicative strategy to mark their property.

Considering only the children who communicated their property claims, the majority of 5-year-olds $(75 \%)$ used the apart strategy for the animal items (moving the stuffed animals to the side, away from the others), whereas they mostly $(67 \%)$ used the mark strategy (i.e., putting something of theirs on the chair) for the chair item. The other three strategies were implemented more rarely, and the stacked strategy was never implemented just by itself. Rather, it occurred only in combination with two other communicative strategies, and only two 5-year-olds used it (see Table S1 in the supplementary materials for details).

Concerning the 3-year-olds, for the item chair, one implemented the mark strategy and another one the central strategy. For the items animals, one 3-year-old implemented an apart + mark strategy.

Both 3- and 5-year-olds used mostly one communicative strategy to communicate property of the object(s; in $85 \%$ of trials, overall). One 3-year-old used two strategies to communicate property (apart + mark), eight 5-year-olds used two strategies (four apart + turned, three apart + mark, and one central + mark), and two 5-year-olds used three strategies (apart + mark + stacked; see Table S2 in the supplementary materials for details). Finally, in $50 \%$ of trials in which children implemented a strategy to communicate property to the absent strangers, they did so as soon as the first prompt had been produced. In $37 \%$ of successful trials, children did so after the second prompt and in $13 \%$ of successful trials after the third prompt had been produced, and they were uniformly distributed across items (see Table S3 in the supplementary materials for details).

\section{Comprehension Phase}

For the respecting property part, we ran a mixed design analysis of variance (ANOVA) including as variables condition (being informed of Lena's prior presence in the room or not), age (3 and 5), and strategy (apart, mark, turned, stacked, central). The main finding was that there was a significant interaction between age and condition, $F(1,76)=6.25, p<.05, \eta^{2}=.08$. The 5-year-olds were less likely to take the stickers in the informed condition than in the ignorant condition, whereas the 3-year-olds did not distinguish between these conditions (see Figure 5). There was no interaction between condition and strategy, $F(4,76)=.26, p=$ $.90, \eta^{2}=.003$, and no three-way interaction between condition, age, and strategy, $F(4,76)=.67, p=.62, \eta^{2}=.01$. There was, however, a significant interaction between strategy and age, $F(4$, 76) $=2.41, p<.05, \eta^{2}=.03$ (see Figure 5 and 6 ). Post hoc Mann-Whitney $U$ test revealed that 3-year-olds were more likely than 5-year-olds to take for themselves the target stickers when faced with the stacked communicative strategy, $U=570$, $z=-2.296, p=.022, r=-.249$, while other pairwise comparisons did not reveal any significant difference between the two age groups with respect to communication strategies (all $p$ values $>$ .18). Post hoc Wilcoxon signed-rank tests conducted for each age group to compare children's performances across strategies revealed that 3-year-olds were more likely to take for themselves the target stickers in the apart and stacked strategies than in the turned and mark ones, and in the stacked strategy rather than in the central one, all $p$ values $<.004$, whereas their performance did not differ across the turned, mark, and central strategy, all $p$ values $>.14$. The 5-year-olds' likelihood of taking for themselves the target stickers was not affected by strategy, all $p$ values $>.07$.

For the identifying property part (designed to control whether children could recognize the different placements/markings of 3 stickers in each chair as ways of communicating property), we ran a mixed design ANOVA including as variables age (3 and 5), strategy (apart, mark, turned, stacked, central), and condition as a control (this refers to being informed about Lena before the taking part; note that all children were told about Lena's presence before being asked to identify the stickers she had chosen). Among the between subject factors, there was a significant main effect of age, $F(1,76)=15.63, p<.001, \eta^{2}=.17$, such that 5-year-olds were generally better than 3-year-olds at identifying which stickers Lena had marked as her own (see Figure 7). As expected, neither the

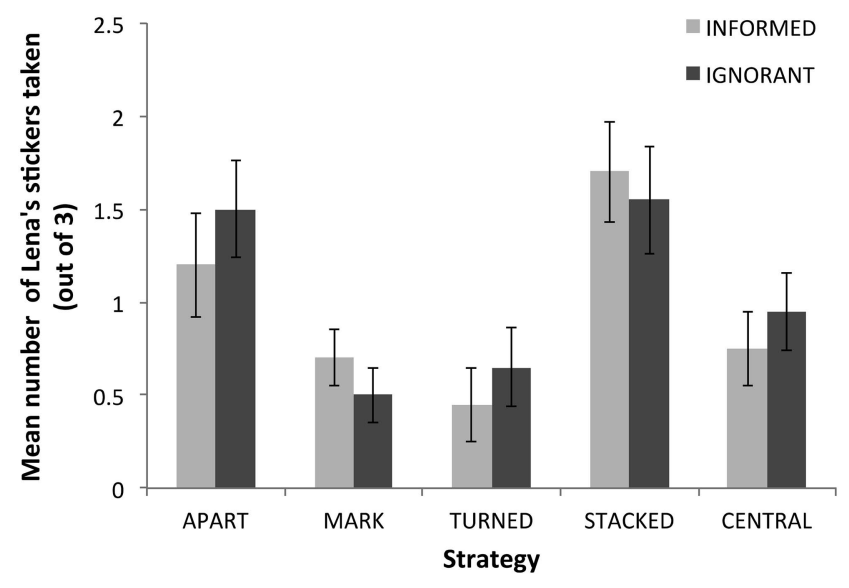

Figure 5. Mean number of Lena's stickers taken by 3-year-olds by condition and strategy. Error bars represent standard error of the mean. 


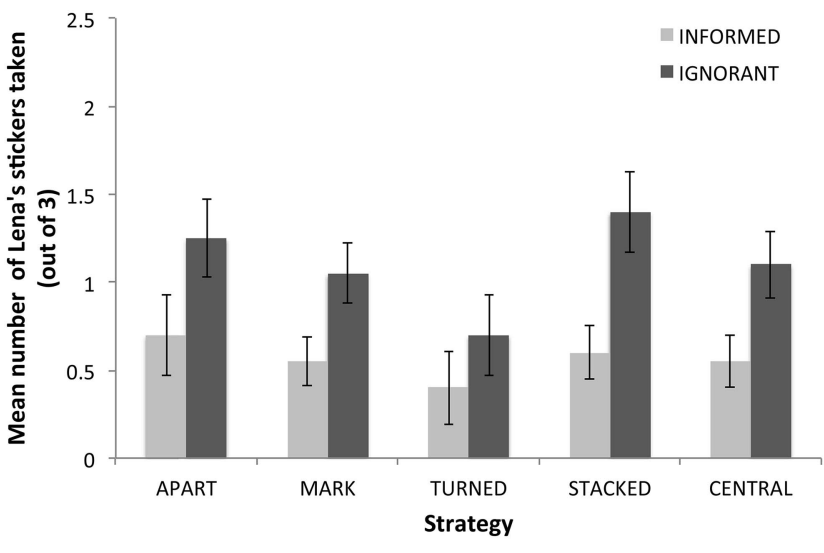

Figure 6. Mean number of Lena's stickers taken by 5-year-olds by condition and strategy. Error bars represent standard error of the mean.

main effect for condition, $F(1,76)=3.08, p=.084, \eta^{2}=.04$, nor the interaction between age and condition, $F(1,76)=2.67, p=$ $.11, \eta^{2}=.03$, were significant, and both had very small effect sizes. Being informed about Lena's prior presence before choosing the stickers (informed) versus after having chosen the stickers (ignorant) made no difference for identifying which stickers she had chosen. Considering the within subject factors, the Mauchly's test of sphericity was violated, $\chi^{2}(9)=33.73, p<.001$, and so we used the Greenhouse-Geisser correction. There was a significant main effect of strategy, $F(3.20,242.87)=10.00, p<.001, \eta^{2}=$ .12. Post hoc Wilcoxon's signed rank pairwise comparisons (with Bonferroni correction) revealed that children were overall better at identifying which stickers Lena had chosen when they were exposed to the strategy apart, compared with all other strategies (apart vs. mark, $T=208.5, p<.001, r=-.363$; apart vs. stack, $T=163, p<.001, r=-.453$; apart vs. turned, $T=185.5, p<$ $.001, r=-.426$; apart vs. central, $T=177, p<.001, r=-.389$; all other pairwise comparisons were not significant; see Table S4 in the supplementary materials for details). None of the interactions was significant: strategy and age, $F(3.20,242.87)=2.47$, $p=.59, \eta^{2}=.03$; strategy and condition, $F(3.20,242.87)=1.40$, $p=.24, \eta^{2}=.02$; strategy, age, and condition, $F(3.20,242.87)=$ $.50, p=.69, \eta^{2}=.01$. The apart strategy was therefore the most recognizable strategy, significantly different from all others, independently of age and when the information about Lena's prior presence in the room was provided.

\section{Discussion}

Overall, the main finding of this study is quite clear. Five-yearolds display much better competence with communicative signals of property than do 3-year-olds. This is true of both production and comprehension.

The results of the production phase show that 5-year-olds are much more likely than 3-year-olds to be able to use communicative strategies to mark objects for property claims. The 5-year-olds use a wider range of strategies than the 3-year-olds, often combining multiple ones simultaneously. They show also a remarkable flexibility in using different strategies depending on what kinds of objects they are claiming for themselves. Indeed, while with the animal trials they tend to move the puppets aside, possibly attempting to hide them, in the chair trials they tend to place something of theirs on the chair. It is possible that the difference in terms of strategies adopted is related to the relative ease of moving the objects around, and moving things is closely related to hiding them, which is the 3-year-olds' preferred strategy. The significant effect of trial shows that having experienced the comprehension phase most likely had a priming effect on the children and facilitated them in communicating property claims over the target items. Given that the participants were never provided any feedback on their recognition of Lena's property claims via spatial markings in the comprehension phase, it cannot be accounted for as learning. Rather, the suggestion is that during the comprehension phase, children were reminded of possible strategies that they could implement in the production phase. The fact that only 5 -year-olds could systematically produce communications about property - and that they were significantly better than 3-year-olds in the identifying part of the comprehension phase-confirms that it is a priming effect for individuals already familiar with the meaning of those communicative signals.

The results of the comprehension phase once again reinforce the strong age difference. When 5 -year-olds were informed that someone had previously entered the room and claimed some stickers, they paid attention to how the stickers were distributed on the chair and interpreted the stickers' physical distribution as a probable property claim. The 5-year-olds therefore avoided choosing the stickers that might have been claimed by another child even though those stickers were clearly appealing (indeed they often picked them when they were not told about the other child). On the other hand, 3-year-olds' choices of stickers were not affected by the information that another child had previously been in the room and claimed some stickers for herself. They seemingly did not recognize the spatial arrangements of objects as any kind of communicative signal at all.

We can think of three main explanations for this striking developmental difference. The first is simply that 3-year-old children have had very little experience with situations in which they must either claim or recognize claims of property in the absence of

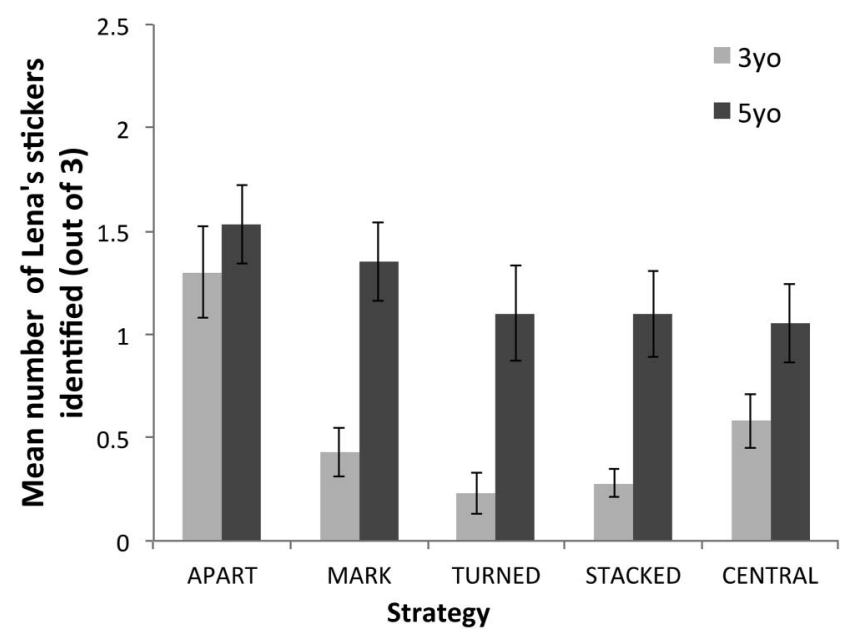

Figure 7. Mean number of Lena's stickers identified by each child (out of 3) by age and strategy. Error bars represent standard error of the mean. 
physical possession. By the time they are 5 years old, young children, especially in Western industrialized countries, have had much more experience with parents writing their names on things for school, adults claiming spaces at the beach by laying down towels, peers claiming objects by gathering them up and placing them in a special place, and so forth. The conventional element in such signals simply takes some time and experience to learn.

The second plausible explanation is related. Children in the modern world do not really own objects themselves. They certainly possess them, and recognize possession in others, but the toys designated as theirs are not their property in the sense that parents do not allow them free reign. Unlike adults who own objects, young children are not allowed to destroy them, deface them, or sell them at will. The children do not really own them, and this may make it difficult for them to distinguish physical possession and ownership proper.

A third possible explanation involves the communicative act. In DeLoache's (1995) account of so-called dual representation problems, 3-year-olds are just beginning to be capable of seeing physical objects as communicative vehicles. For example, they struggle to see a dollhouse as a representation, part by part, of a real house; it is first and foremost a physical object to be manipulated. And so it is possible that in the current study, the 3-year-olds have difficulty seeing the stickers, in the comprehension phase, and the animals and chairs, in the production phase, as both physical objects to be manipulated and at the same time communicative vehicles. Of course, this would be compounded by the fact that they have not had much experience producing or comprehending objects as communicative vehicles either.

Finally, if we consider the degree of recognition of specific strategies in the comprehension phase and the likelihood of implementing them in the production phase, we can attempt to establish a preliminary order of signal development and use. On a continuum from more "natural" to more conventional, the apart strategy would seem to be most natural. It has many similarities with simply hiding objects or obstructing access to them (as in animal caching), and it is the one that seems to be recognized best by 3 -year-olds. The strategy central concerns placing things in the middle or closer to each other (similar to hoarding), and so would seem fairly natural as well. Turning objects upside down might be natural in that it might prevent others from noticing the main features of that object, yet its use only in the chair trials by 5-year-olds suggests a more conventionalized use, associated with placing the chair in a position noticeably different from its most common position while entering a room. The mark strategy of claiming property by placing an object already belonging to oneself on it would seem to be most conventional. Most likely, it is learned observationally from others between ages 3 and 5. Finally, piling things up (stacked strategy) does not appear to be as clear a property claim as one would expect. Indeed, only 5-year-olds use it and only in combination with other strategies. One possible explanation is that in piling things up, the objects become more noticeable, and therefore attract more attention. While this might be positive if piling things up is recognized as a claim, if ignored it might result in strangers being more likely to take those objects away, as can be observed in the stacked strategy in the comprehension phase for 3-year-olds and for 5-year-olds (but for the latter only if they are ignorant about Lena's prior presence in the room).
The current study is only a first step in determining the role of communication and cooperation in children's developing understanding of ownership as a socially normative institution. At the moment, we can only speculate about the basis of the developmental pattern observed. Related to this is the specific open question about whether 5-year-olds in the production phase take into account the fact that they are going to communicate to other children and not adults. The fact that a few children use multiple communicative strategies simultaneously suggests that they might entertain the possibility of misunderstanding or lack of recognition and therefore use redundancy as a solution to this problem, but this is something that could be systematically manipulated. Also, at the moment, our developmental ordering of communicative signals of ownership is quite tentative. We have proposed a continuum from more natural to more conventional, but to really nail this down would require more systematic testing. In addition, toward the same end, cross-cultural studies would help to answer the naturalconventional question as well.

Overall, these results show that by 5 years of age, young children understand the crucial role of communication and cooperation in asserting property claims. Not only do they reliably know how to mark some objects as their property, but they also appear to respect such claims from others if they have a reason to consider some objects' spatial position to be a possible communicative signal from those others. These results point to a developmental trajectory in which young children begin with a strong notion of physical possession (see Rochat, 2014), and then only gradually come to understand the related but distinct notion of ownership. As they develop a notion of ownership as a cooperative agreement among people about objects that transcends physical possession, they come to see the communicative dimension of the process as not just conveying information but rather as helping to constitute the agreement itself.

\section{References}

Altman, I. (1970). Territorial behavior in humans: An analysis of the concept. In L. A. Pastalan \& D. A. Carson (Eds.), Spatial behavior of older people (pp. 1-24). Ann Arbor: University of Michigan Press.

Ardrey, R. (1966). The territorial imperative. New York, NY: Atheneum.

Becker, F. D. (1973). Study of spatial markers. Journal of Personality and Social Psychology, 26, 439-445. http://dx.doi.org/10.1037/h0034442

Blake, P. R., Ganea, P. A., \& Harris, P. L. (2012). Possession is not always the law: With age, preschoolers increasingly use verbal information to identify who owns what. Journal of Experimental Child Psychology, 113, 259-272. http://dx.doi.org/10.1016/j.jecp.2012.06.008

Blake, P. R., \& Harris, P. L. (2009). Children's understanding of ownership transfers. Cognitive Development, 24, 133-145. http://dx.doi.org/ 10.1016/j.cogdev.2009.01.002

Carpenter, C. R. (1958). Territoriality: A review of concepts and problems. In A. Roe \& G. G. Simpson (Eds.), Behavior and evolution (pp. 224 250). New Haven, CT: Yale University Press.

DeLoache, J. S. (1995). Early understanding and use of symbols: The model model. Current Directions in Psychological Science, 4, 109-113. http://dx.doi.org/10.1111/1467-8721.ep10772408

Edney, J. J. (1974). Human territoriality. Psychological Bulletin, 81, 959975. http://dx.doi.org/10.1037/h0037444

Edney, J. J., \& Jordan-Edney, N. L. (1974). Territorial spacing on a beach. Sociometry, 37, 92-104. http://dx.doi.org/10.2307/2786469

Eisenberg-Berg, N., Haake, R., \& Bartlett, K. (1981). The effects of possession and ownership on the sharing and proprietary behaviours of 
preschool children. Merril-Palmer Quarterly, 27, 61-68. Retrieved from http://www.jstor.org/stable/23084509.

Eisenberg-Berg, N., Haake, R., Hand, M., \& Sadalla, E. (1979). Effect of instructions concerning ownership of a toy on preschoolers' sharing and defensive behaviours. Developmental Psychology, 15, 460-461. http:// dx.doi.org/10.1037/0012-1649.15.4.460

Friedman, O., \& Neary, K. R. (2008). Determining who owns what: Do children infer ownership from first possession? Cognition, 107, 829849. http://dx.doi.org/10.1016/j.cognition.2007.12.002

Friedman, O., Van de Vondervoort, J. W., Defeyter, M. A., \& Neary, K. R. (2013). First possession, history, and young children's ownership judgments. Child Development, 84, 1519-1525. http://dx.doi.org/10.1111/ cdev. 12080

Gelman, S. A., Manczak, E. M., \& Noles, N. S. (2012). The nonobvious basis of ownership: Preschool children trace the history and value of owned objects. Child Development, 83, 1732-1747. http://dx.doi.org/ 10.1111/j.1467-8624.2012.01806.x

Goffman, E. (1971). Relations in public: Microstudies of the public order. New York, NY: Harper and Row.

Hay, D. F. (2006). Yours and mine: Toddlers' talk about possessions with familiar peers. British Journal of Developmental Psychology, 24, 39-52. http://dx.doi.org/10.1348/026151005X68880

Hook, J. (1993). Judgments about the right to property from preschool to adulthood. Law and Human Behavior, 17, 135-146. http://dx.doi.org/ 10.1007/BF01044542

Kanngiesser, P., Gjersoe, N., \& Hood, B. M. (2010). The effect of creative labor on property-ownership transfer by preschool children and adults. Psychological Science, 21, 1236-1241. http://dx.doi.org/10.1177/ 0956797610380701

Kanngiesser, P., \& Hood, B. M. (2014). Young children's understanding of ownership rights for newly made objects. Cognitive Development, 29, 30-40. http://dx.doi.org/10.1016/j.cogdev.2013.09.003

Keil, F. C., Gelman, S. A., Noles, N. S., \& Bloom, P. (2012). Children's and adults' intuitions about who can own things. Journal of Cognition and Culture, 12(3-4), 265-286. http://dx.doi.org/10.1163/1568537312342076

Kim, S., \& Kalish, C. W. (2009). Children's ascriptions of property rights with changes of ownership. Cognitive Development, 24, 322-336. http:// dx.doi.org/10.1016/j.cogdev.2009.03.004

Lorenz, K. (1966). On aggression. New York, NY: Harcourt, Brace \& World.

Neary, K. R., Friedman, O., \& Burnstein, C. L. (2009). Preschoolers infer ownership from "control of permission." Developmental Psychology, 45, 873-876. http://dx.doi.org/10.1037/a0014088
Neary, K. R., Van de Vondervoort, J. W., \& Friedman, O. (2012). Artifacts and natural kinds: Children's judgments about whether objects are owned. Developmental Psychology, 48, 149-158. http://dx.doi.org/ $10.1037 / \mathrm{a} 0025661$

Nozick, R. (1974). Anarchy, state, and utopia. New York, NY: Basic books.

Rochat, P. (2014). Origins of possession: Owning and sharing in development. New York, NY: Cambridge University Press. http://dx.doi.org/ 10.1017/CBO9781139424608

Rose, C. M. (1985). Possession as the origin of property. The University of Chicago Law Review, 52, 73-88. http://dx.doi.org/10.2307/1599571

Rose, C. M. (2007). The moral subject of property. William and Mary Law Review, 48, 1897-1926. Retrieved from http://heinonline.org/HOL/ LandingPage handle $=$ hein .journals $/ \mathrm{wmlr} 48 \& \operatorname{div}=50 \& i d=\& \mathrm{p} .=$

Ross, H. S. (1996). Negotiating principles of entitlement in sibling property disputes. Developmental Psychology, 32, 90-101. http://dx.doi.org/ 10.1037/0012-1649.32.1.90

Ross, H. S. (2013). Effect of ownership rights on conflicts between toddler peers. Infancy, 18, 256-275. http://dx.doi.org/10.1111/j.1532-7078 .2012.00121.x

Rossano, F., Rakoczy, H., \& Tomasello, M. (2011). Young children's understanding of violations of property rights. Cognition, 121, 219-227. http://dx.doi.org/10.1016/j.cognition.2011.06.007

Rossano, F., \& Tomasello, M. (2014). Preschoolers' understanding of trash and the relinquishing of property. Manuscript submitted for publication.

Shaffer, D. R., \& Sadowski, C. (1975). This table is mine: Respect for marked barroom tables as a function of gender of spatial marker and desirability of locale. Sociometry, 38, 408-419. http://dx.doi.org/ $10.2307 / 2786174$

Singer, J. W. (2010). Property law: Rules, policies \& practices (5th ed.). New York, NY: Aspen Publishers.

Smetana, J. (1984). Toddlers' social interactions regarding moral and conventional transgressions. Child Development, 55, 1767-1776. http:// dx.doi.org/10.2307/1129924

Sommer, R., \& Becker, F. D. (1969). Territorial defense and the good neighbor. Journal of Personality and Social Psychology, 11, 85-92.

Sugden, R. (1986). The economics of rights, co-operation and welfare. Oxford: Basil Blackwell.

Sugden, R. (1989). Spontaneous order. The Journal of Economic Perspectives, 3, 85-97. http://dx.doi.org/10.1257/jep.3.4.85

Received May 14, 2014

Revision received October 6, 2014 Accepted October 22, 2014 